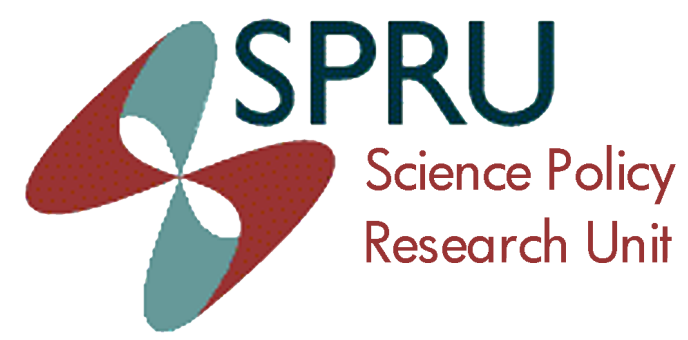

Working Paper Series SWPS 2014-15

August, 2014

\title{
Taste and Power: \\ the flavouring industry and flavour additive regulation
}

\section{Patrick van Zwanenberg}

Erik Millstone 


\section{SPRU Working Paper Series}

The SPRU Working Paper Series aims to accelerate the public availability of the research undertaken by SPRU-associated people of all categories, and exceptionally, other research that is of considerable interest within SPRU. It presents research results that in whole or part are suitable for submission to a refereed journal, to a sponsor, to a major conference or to the editor of a book. Our intention is to provide access to early copies of SPRU research.

\section{Editors}

Tommaso Ciarli

Daniele Rotolo

Associate Editors

Florian Kern

Paul Nightingale

Matias Ramirez

Joe Tidd \&

Carlos Sato

Maria Savona \&

Mariana Mazzucato

Andrew Stirling Transitions

Caitriona McLeish Civil military interface

\section{Area}

Energy

\section{Contact}

T.Ciarli@sussex.ac.uk

D.Rotolo@sussex.ac.uk

F.Kern@sussex.ac.uk

P.Nightingale@sussex.ac.uk

Matias.Ramirez@sussex.ac.uk

J.Tidd@sussex.ac.uk

C.E.Y.Sato@sussex.ac.uk

M.Savona@sussex.ac.uk

M.Mazzucato@sussex.ac.uk

A.C.Stirling@sussex.ac.uk

C.A.McLeish@sussex.ac.uk

\section{Disclaimer}

The works available here are the responsibility of the individual author(s) and do not necessarily represent the views of other SPRU researchers. As matters of policy and practice, SPRU does not endorse individual research contributions.

\section{Guidelines for authors}

Papers shall be submitted in pdf or Word format. They should contain a title, an abstract, and keywords. Papers should be submitted to one of the Editors, who will process them and send them to the appropriate Associate Editor. Two members of SPRU will be asked to provide a short written review within three weeks. The revised versions of the paper, together with a reply to the reviewers, should be sent to the Associate Editor, who will propose to the Editors its publication on the series. When submitting the authors should indicate if the paper has already undergone peerreviewing, in which case the Associate Editors may decide to skip internal review process.

\section{Website}

SWPS: www.sussex.ac.uk/spru/research/swps

IDEAS: ideas.repec.org/s/sru/ssewps.html 


\title{
Taste and Power: the flavouring industry and flavour additive regulation
}

\author{
Patrick van Zwanenberg ${ }^{(a)} \&$ Erik Millstone ${ }^{(b)}$ \\ (a) Centro de Investigaciones para la Transformación (Cenit) \\ Callao $3533^{\circ} \mathrm{B}$, Ciudad de Buenos Aires (CP C1022AAD), Argentina. \\ pvz@,fund-cenit.org.ar
}

(b) SPRU - Science and Technology Policy Research, University of Sussex, Brighton, BN1 9RQ, UK.

e.p.millstone@sussex.ac.uk

June 2014

Revised manuscript for 'Science as Culture'

Acknowledgements: we are grateful to two anonymous referees and to the journal editors for their helpful comments on an earlier version of this paper. 


\begin{abstract}
The concepts and methods used by regulatory agencies worldwide to assess the safety of flavouring additives were designed by and for the flavouring industry. They embody, and embed in routine regulatory practice, the industry's commercial interests in minimising the costs of regulatory oversight and the risks that the market for its products might be restricted. First sketched out by US flavouring company scientists in the early 1960s, the approach required almost no experimental data, and was highly permissive, relative to both our knowledge (and lack of it) about chemical toxicity, and to the ways other kinds of food additives are regulated. Our distinctive 'realist constructivist' analysis illustrates how the industry's approach was also antiscientific, unscientific because it served to discourage scientific investigation of important aspects of the phenomena it purported to evaluate, and because it relied on hypotheses that lacked any evidential basis. The approach was first used to assess flavourings in the USA, where the industry was allowed to design and run its own regulatory regime. In all other regulatory jurisdictions, the industry's approach was rejected; expert advisors argued that it was incompatible with mandates to protect consumer health. Yet, the approach eventually prevailed everywhere. It did so in large part because of the collective refusal of the flavouring industry over three decades to provide the experimental data that had been requested by the regulatory authorities. This has been a form of regulatory capture, which was triggered by a remarkably effective tactic of non-cooperation with demands for data.
\end{abstract}




\section{Introduction}

Flavourings are cosmetic additives that are used in processed food and drink products. They are used extensively by the food industry, partly to disguise unpleasant flavours and odours created by processing, but especially to minimise costs by enabling cheap ingredients, such as fats, sugars and carbohydrates, to appear as if they came from expensive and tasty ones, such as fruit, coffee or chocolate. Flavouring additives are often defined as substances that are intentionally added to food in order to impart taste or odour sensations, but that are not intended to be consumed as such. (CEC 2008) Raw foods that have not undergone any processing, and that are used as flavour ingredients, are therefore excluded (although this does not usually apply to spices and herbs). ${ }^{1}$ Similar provisions apply to cooked foods, so that cooked strawberries that give strawberry jam its flavour are counted as a food ingredient rather than as an additive or a flavouring. If however, strawberries are processed, and their essential flavouring compounds are distilled, that distillation would count as a flavouring additive, as would synthetic chemicals selected to imitate the taste of strawberries. Flavouring substances include chemicals derived from plant or animal sources, synthesized equivalents of those substances, and chemicals that do not occur naturally - or as the flavouring industry sometimes likes to characterise the latter, as substances 'that have not yet been identified in nature'. (Hallagan \& Hall, 1995, 428)

A curious feature of public policy for flavourings is that the approach used to assess the safety of flavouring compounds differs entirely from that used to assess the safety of other classes of food additive, such as colours, sweeteners and preservatives. The latter are typically required to undergo a series of toxicological tests designed to identify various forms of possible acute, sub-chronic and chronic toxicity. Flavourings, on the other hand, are assessed on the basis of an approach which involves no or very minimal toxicological testing; one created by scientists working for or on behalf of the flavouring industry. That approach is routinely portrayed by the flavouring industry, its expert advisors and, since the late 1990s, by most regulatory institutions, as providing an adequate and appropriate scientific basis by which to reach informed judgements about flavouring safety. (WHO, 1997; SCF, 1999; Smith et al, 2005)

In this paper we are interested in whether involvement of scientists employed or commissioned by the flavouring industry in the design of the regulatory approach for assessing flavouring safety has mattered, and if so how? Taking an historical overview of the development of flavouring regulation, beginning in the late 1950s, in the USA, UK, the European Community and Union, and at the Codex Alimentarius Commission, we ask the following questions: How did scientists working for the flavouring industry contribute to the development of a novel approach to assessing

\footnotetext{
${ }^{1}$ ). Substances that impart an exclusively sweet, sour or salty taste are also not usually considered to be flavouring additives (eg sugar substitutes which are regulated separately as sweeteners).
} 
flavouring safety? In what ways, if any, have the commercial interests of the flavouring industry shaped the development and substance of that approach? How did the industry manage to persuade globally influential regulatory agencies to sanction and adopt its preferred approach? And what are the consequences of reliance on that approach, not just for regulatory outcomes, but also for the quality and extent of our knowledge about flavouring toxicity?

\section{Conceptual and methodological background}

Scholarship in the field of science and technology studies (STS), drawing on numerous case examples, has shown that many stages in the production of policyrelevant scientific knowledge are under-determined by evidence. These span the initial definition and bounding of problems, research questions and objects of investigation, and continue through to the design, conduct, interpretation and reporting of experimental work. (Jasanoff \& Wynne, 1998) The production of regulatory scientific knowledge must therefore involve a series of normative choices, inferences, and assumptions, the selection of which (whether habitual, deliberate or opportunistic) will reflect social values from some source or sources. In practice many of those choices, inferences and assumptions, and the underlying values and interests that give rise to those judgements, are not usually subject to wider deliberation or justification. (Wynne, 1992; Stirling 2008) Instead they may be unrecognised, or sometimes even denied or knowingly concealed, or just glossed over under the political pressure to provide seemingly socially neutral knowledge for policy.

STS scholars and other regulatory analysts have often responded to this kind of analysis, as is our intention in this paper, by 'deconstructing' regulatory science - by identifying indeterminate or empirically under-determined aspects of knowledge claims, making explicit the key choices, assumptions and inferences that have been invoked, and then seeking to explain the selection of those subjective commitments by reference to wider contextual values, interests and cultural norms. (Gillespie et al, 1979; Jasanoff, 1987; Latin, 1988; Wynne, 1992)

One strand of this literature has focused on how the social interests of corporate actors contribute to shaping regulatory knowledge, particularly via industrial involvement in the conduct of scientific studies, and in the evaluation of experimental data. (Abraham, 1993; Huff, 2002; Michaels, 2008) In many policy arenas, regulated industries, or commissioned third parties, design and perform experimental studies, interpret and ascribe meaning to study findings, review broader scientific literatures, challenge regulatory institutions' interpretations of data, and even draft the overall assessments that form the basis of regulatory agencies' decisions. (Castleman \& Ziem, 1988; Zeltner et al, 2000) STS work on this theme often stresses how interpretative flexibility means that there is ample scope for corporate actors to 
perform those elements of individual regulatory evaluations in ways that further their interests and agendas. (Sismondo, 2008)

A much less common focus within this strand of work, but one we adopt in this paper, analyses how industrial interests may contribute to the social shaping of regulatory science at a more 'upstream' stage, in terms of influence over the development of the concepts and methods through which regulatory scientific work is undertaken (see, for example, Abraham \& Ballinger 2012) This is a potentially more fundamental route for the influence of corporate values over the construction of regulatory scientific knowledge, partly because it has implications for all regulatory scientific assessments, within a particular field, but also because it is likely to be far less visible. By influencing general regulatory principles and methods, industrial values tend to become embedded within regulatory-scientific practice, requiring no on-going involvement of industrial expertise in regulatory appraisal.

Our deconstruction of the concepts and methods for assessing flavouring safety is based on a textual analysis of a wide range of academic, trade and regulatory documents, both published and unpublished, that discuss the development, rejection and/or adoption of the industry's approach to assessment. The type of textual analysis on which our account is based reflects the tradition characterised by van Dijk (1993) as 'Critical Discourse Analysis', which is concerned with the revealing the ways in which social power is expressed, enacted and legitimated in text or talk. In line with that tradition, we have scrutinised the writings and speeches of key protagonists. By tracing the patterns of the arguments provided in those sources, we have identified some of the key non-scientific assumptions that have framed their scientific perspectives. We have moreover highlighted the congruence between the stated commercial interests and practices of the flavourings industry and the scientific narratives that they have articulated and contested, and the ways in which those narratives have correlated with the actions of those firms.

The texts on which we have concentrated includes series of UK, EU and Codex exert advisory committee reports on food additives, and a number of articles in Food, Drug, Cosmetic Law Journal, which published commentaries by both regulators and the food and flavouring industry during and after the introduction of the 1958 Food Additives Amendment in the USA. The unpublished documents consist of papers, memos and conference proceedings, mainly written by flavouring and tobacco industry scientists and executives, that have become publicly accessible as a result of tobacco litigation (flavouring compounds are used in the manufacture of cigarettes). The source is an on-line database of 14 million documents organized by the Legacy Tobacco Documents Archive at the University of California, San Francisco. ${ }^{2}$

\footnotetext{
${ }^{2}$ http://legacy.library.ucsf.edu
} 
Based on those documents, we outline the reasoning underpinning the novel approach to assessment developed by flavouring industry scientists and we make explicit the key choices, inferences and assumptions adopted within that approach (sometimes made explicit by the authors or otherwise apparent from regulatory debates, as well as competing approaches and our own understanding of the regulatory-scientific field). We examine the nature of the empirical support for that reasoning; the degree to which that reasoning was shared by regulatory advisors and officials and why; and we make an assessment of the implications of that novel approach for learning about flavouring toxicity and safety. We also sought wider evidence, especially from articles and speeches by flavouring industry scientists, which might explain why particular sets of choices, assumptions and inferences were made or invoked, and not others, during the development of the industry's flavouring assessment approach.

Few STS scholars reflect on what we might sometimes learn from analytical 'deconstruction' exercises about the scientific status or relative reliability of particular knowledge practices and claims. Norms of methodological symmetry with respect to the truth-value of scientific knowledge claims typically rule out such lines of analysis. (Bloor 1976) Our analysis, by contrast, is grounded in a realist interpretation of constructivism; one in which the choice-laden nature of science is not treated, methodologically, as if it were entirely unlimited, or constrained only by social convention. Instead, empirical evidence and some scientific standards, particularly those that are common across disciplines and time, may impose limits on what scientists and others might otherwise wish to believe. (van Zwanenberg \& Millstone, 2000) Careful scrutiny of knowledge practices and claims in regulatory contexts suggests that they can and do depart from what are basic, very widely held community norms and standards; for example, the idea that one of the criteria that renders a knowledge claim scientific is that it should have some kind of empirical support rather than none at all, or standards of consistency, such that, for example, studies indicating a toxic effect and studies indicating the absence of such an effect, should both be scrutinised - equally rigorously - for potential methodological flaws. (Ashford et al, 1983; Abraham, 1993; Wickson \& Wynne, 2012) In circumstances where such norms and standards are not adhered to, as we shall argue are apparent in this case study, STS scholars can make empirically-grounded normative judgements about the scientific status or reliability of regulatory knowledge practices and claims in ways that are relatively straightforward.

We find helpful the basic meaning of 'regulatory capture' - of cases where what regulators decide and how they perform is what the regulated industry would like them to decide, and how the industry would like them to perform (Mitnick, 2011). Multiple mechanisms of capture have been identified, including a 'revolving door' of scientists and other personnel between an industry and its regulator, and control over the supply and meaning of knowledge by the regulated industry. (Mitnick, 2011; Shapiro, 2012) We shall argue that whilst variants of those mechanisms contributed to what is a case of regulatory capture, in this context it was not a matter of industry 
influencing the performance and decisions of a pre-existing regulatory regime, but rather a case of creating its own regulatory framework, to avoid regulatory costs and restrictions, and then persuading policy-makers to adopt and internalize that framework.

\section{A regulatory history of flavourings}

Regulatory attention was first directed at flavourings in industrialised countries at the beginning of the second half of the twentieth century, in response to the explosion in the numbers of new colours, sweeteners, flavourings, and other substances added to processed food. Statutes then in force in several countries prohibited the use of additives in food that were harmful, but the food industry was not required to demonstrate the absence of harm before using a new additive. By the 1950s there were hundreds of colours, preservatives and sweeteners and flavourings in commercial use, for which there existed no experimental evidence of safety. (Oser, 1957)

\section{A self-regulatory regime for flavours in the USA}

In the USA, years of Congressional hearings on food additives culminated in the landmark 1958 Food Additives Amendment to the US Food, Drug and Cosmetic Act. The amendment prohibited the use of additives in food that had not obtained premarket approval by the Food and Drug Administration (FDA). To obtain approval, additive manufacturers were expected to provide the FDA with a range of experimental data, including from toxicological studies on laboratory rodents that the FDA's Division of Pharmacology had developed in the 1930s and '40s, and with which it had identified the toxicity of a number of substances that had previously been in widespread (but presumed safe) use in medical, cosmetic and food products. (Lehman et al, 1955)

Excluded from the definition of food additive were substances that the Amendment termed 'generally recognised as safe', or GRAS. The intention was to minimise the burden on the food industry (and the FDA) of having to test (and evaluate and approve) all chemical compounds added to food, as well as common food ingredients such as pepper, salt, and mustard. (Dengan 1991; Noah \& Merrill, 1998) A substance could be classified as GRAS if it was 'generally recognized among experts' as 'safe' for its intended use. The basis of such expert judgment could be either 'experience based on common use in food' for substances in use before 1958, or 'scientific procedures' for substances first used after 1958.

Shortly after the new bill became law, Richard Hall, chair of the Food Additives Committee of the trade association of the US flavouring industry, the Flavor and 
Extracts Manufacturers Association (FEMA), explained to colleagues at a food law conference how FEMA wished, where possible, to ensure that food flavours were exempt from the food additive regulation by ascribing GRAS status to them, so avoiding any need to test them toxicologically.

Hall argued that since the key factors in determining GRAS, such as 'common use', 'safe' and 'scientific procedures' were all subjective, their interpretation should not be left to the discretion of the FDA. (Hall 1960a, 36) Instead he argued that "[ $\mathrm{t}] \mathrm{h}$ ese factors must be determined by our ... experts..." (Hall 1960a, 36; emphasis added) thereby revealing that FEMA had no illusions about the neutrality of its 'experts'. The new legislation had not defined which kinds of experts were permitted to classify a substance as GRAS and so there appeared to be nothing in principle to prevent the food and chemicals industries from characterising their own products as GRAS.

(Degnan, 1991)

Hall made clear what was at stake: “...[I]f an unrealistic standard of safety is applied to many hundreds of these low level, low volume flavors and they are dropped from use, there will be a serious decrease in quality in many hundreds of food products, and a number of firms will face disabling or fatal financial loss... (Hall 1960a, 33) He was also explicit about how he thought discretion over the determination of GRAS should be exercised because he told his audience that hundreds of flavouring ingredients "... are used at levels that are too low and in a total volume which is too small to have any possible toxicological significance..." (Hall 1960a, 34) He also argued that "we should not accept arithmetic manipulation [i.e. interpretations of data from toxicity tests in laboratory animals] as a substitute for informed judgement." (Hall 1960a, 33)

The following year Hall and a few other flavouring company scientists on FEMA's Food Additives Committee, produced a long list of flavouring substances for a food industry conference that they considered 'toxicologically insignificant, and therefore GRAS'. (Hall, 1960b)

FEMA had classified flavours as GRAS if they either:

- occurred naturally in food

- had a 'long history of widespread and apparently safe use (e.g. 30 years by several companies)'

- had a 'known ease of metabolism in the body'

- possessed a 'close structural relationship to another substance known to be safe', or

- had been in use for at least 10 years by more than one company and were not used in any food stuff at levels of more than 10 parts per million, and annual national consumption was less than $1000 \mathrm{lb}$, and there were no 'unfavourable indications from structure, composition, or experience in use which would cast doubt on [their] safety. 
Notably, experimental evidence, except perhaps for metabolic data, did not appear in those criteria. FEMA's proposed criteria were contentious, even amongst the small professional community of scientists involved in food additive regulation. For example, the claim that 'a long history of widespread and apparently safe use' could be equated with toxicological insignificance had been rejected three years earlier by Bernard Oser, head of a toxicology consultancy who was later to be employed by FEMA, and who subsequently played a key role in FEMA's self-regulatory regime. In 1957 Oser had said that:

“...with respect to certain ...flavouring compounds, usage alone - however prolonged - should not justify exemption [from the then proposed Food Additives Amendment]. The hazards of some of these compounds may have escaped detection." (Oser 1957, 202-203)

Likewise, the claim that flavours could be considered toxicologically insignificant if they had a 'close structural relationship to another substance known to be safe' had been specifically rejected by the FDA's Division of Pharmacology in 1955, in guidance outlining how the FDA expected food additives, cosmetics and drugs to be tested by industry. That guidance had noted that there is often a:

"...hope that if one member of a class of organic compounds is found to be safe for a given use other members will be equally safe; costly toxicity tests could be avoided. Such a hope is absolutely unreliable... Seemingly insignificant changes in the structure of organic molecules may produce drastic changes in toxicity." (Lehman et al 1955, 683; emphasis added)

Hall and his colleagues recognised that FEMA's proposed GRAS list might not be considered by the FDA as 'generally recognised' and so announced that an 'independent' panel of scientists would be established to produce such a list. (Hall, 1960b) The membership of the panel was selected by Bernard Oser, by then employed by FEMA as a consultant, who was also appointed its non-voting chair. The panel comprised six scientists, three working in academia and three in industry. (Oser \& Ford, 1991) Richard Hall of FEMA was appointed as Secretary to the panel.

In 1965, the panel published a list of 1,124 flavours that it considered GRAS, all of which were accepted by the FDA as permitted for use in food. (Hall \& Oser, 1965) As an FDA official later explained, the vast majority of those flavours, 1,118, had been in use prior to the date that the Food Additives Amendment came into force, and had been classified as GRAS by the panel on the basis of 'experience based on common use in food'. (Lin, 1991, 881) Although that criterion was permitted by the legislation - for substances in use prior to 1958 - it meant that the panel effectively assumed that those flavours could not give rise to anything but immediate acute toxic effects. Any other effects could not conceivably have been identified by 'experience' alone. 
In turned out that several flavourings that had been designated as GRAS by the FEMA panel on the basis of experience of common use were subsequently found to be animal carcinogens in studies that had been planned, funded and conducted by public sector institutions in the USA. They included calamus oil, used to flavour alcoholic drinks and cinnamyl antraniliate, used to flavour ice cream and sweets. Both were subsequently banned for use in food by the FDA. (Lewis 1989, 14) Whilst the magnitude of the carcinogenic risk posed to humans by exposure to those compounds is uncertain, the key point here is that the evaluation by the FEMA panel could never have identified the carcinogenic hazards of those flavours. Moreover, FEMA's evaluation constituted a disincentive for relevant and potentially revealing toxicity studies to be conducted or funded by FEMA's members. In that respect the FEMA panel's approach, which claimed to be reliably assessing flavour safety, (Hall \& Oser 1961, 23; Hall \& Oser 1968, 6) as opposed to merely grandfathering in existing compounds, was 'anti-scientific'.

\section{The FEMA panel's 'scientific procedures'}

The remaining 6 flavourings in the FEMA panel's 1965 list were classified as GRAS on the basis of 'scientific procedures', as required by the new legislation. (Lin 1991, 882) Also, after 1965 the panel continued to publish lists of GRAS flavours (all of which were subsequently treated by the FDA as permitted for use in food). Since these new lists comprised novel flavouring substances, such judgements should also have been made by reference to 'scientific procedures'.

The panel had outlined a very brief account of how it had chosen to define those procedures in 1961. They were, in most respects, indistinguishable from the approach outlined by Hall and his flavour industry colleagues in 1960. Natural occurrence in food, assumed metabolic fate, chemical structure, and usage levels were listed as criteria by which safety judgements would be made, although with one exception they were described not in the form of decision rules, but as types of information contributing to GRAS judgements. The exception concerned usage levels, where the panel adopted essentially the same decision rule as FEMA had the previous year (i.e. some flavours used at concentrations of less than 10 parts per million can be considered toxicologically inconsequential). The panel did however include a criterion of toxicity data in their intended approach. It nevertheless noted that toxicity data were only very rarely available. (Hall \& Oser, 1961)

In 1977 a more detailed, but still rather obtuse, description of the panel's approach to reaching GRAS judgements about new flavours was provided in a paper by Oser and Hall (1977), after the FDA had complained that the criteria used by the panel were not 'generally known'. (Oser \& Hall 1991, 94) In that paper, Oser and Hall explained that the threshold concentration of 10 parts per million in food, below which the panel, 
and FEMA before it, had previously considered certain flavours to be 'toxicologically inconsequential', was now re-interpreted as an average daily estimated intake of $2 \mathrm{mg}$ per day, although no reasons were given explaining why that change had been made. Using language which effectively discounted any need for experimental data, Oser and Hall explained that in addition to an average intake of less than $2 \mathrm{mg}$ per day, the structure of the candidate flavour "....must suggest that it will be readily handled through known metabolic pathways and will be excreted without toxic effect" and "...it must be a member of a structurally related group that, without known exception, is or can be presumed to be of low toxicity." (Oser and Hall $(1977,462)$ [emphasis added]

Oser and Hall went on to explain that whilst estimated intake was decisive, "...structure and metabolic fate are usually the primary factors considered in safety evaluation ...." (Oser and Hall $(1977,462)$ By reference to those factors the authors argued that all flavourings could be allocated into three classes:

I. "Compounds of simple organic structure that are readily handled through known metabolic pathways and without adverse biochemical, physiological or pharmacological effect.

II. Compounds structurally analogous to those in class I and whose metabolic fate can also reasonably be assumed not to be associated with adverse biochemical, physiological or pharmacological effect.

III. Compounds with structures so different from those in classes I and II that reasonable assumptions regarding metabolic fate and freedom from the possibility of adverse effect are precluded." (Oser \& Hall $(1977,460)$

It is noteworthy that Class I was not defined as compounds known to be metabolised through known pathways and known to be without adverse toxic effects, but rather as if it was always possible reliably to make assumptions about the pathways along which they would be metabolised, and to equate such pathways with the absence of toxicity. As Oser and Hall explained, they were assuming that: "[ $t]$ he metabolism of a compound of known structure can in most cases be inferred from known data on the metabolism of a related compound." (Oser and Hall 1977, 463) And that: "[g]iven the chemical structure of a flavouring compound, available information concerning its metabolism and the biotransformations it may undergo play a predominant role in assessing its potential toxicity." (Oser and Hall 1977, 462)

Similar assumptions were invoked for Class II compounds. Oser and Hall (1977, 460) explained that: 
"[s]ubstances falling into class II are assumed to be metabolized in a manner similar to their close structural analogues in class I. Even where direct experimental evidence itself is lacking, a presumption of safe biotransformation at low levels of intake based largely on reasoning by analogy appears fully justified." [emphasis added]

The term 'reasoning by analogy' referred to inferences from other chemicals, deemed to be structurally similar, for which short-term toxicity data were available.

Thus neither toxicity nor metabolic data (or indeed any experimental data) were necessary to allocate individual flavours to Classes I or II. All could then be regarded, Oser and Hall postulated, as safe at unspecified 'low levels of intake' (presumably at or below an estimated average of $2 \mathrm{mg}$ per day). Oser and Hall $(1977,460)$ claimed that the 'great majority' of flavours fell into Classes I and II. For the few remaining compounds, allocated to Class III, Oser and Hall explained that toxicity data might be required to reach judgements about safety, but such data need only come from a 14 day toxicity test using one dose, so long as there existed data from a long term study on "....at least one member of the closely related group". (Oser and Hall 1977. 464)

Oser and Hall represented the FEMA panel's approach as 'far more useful' than performing toxicological studies on each compound, and capable of making 'quite valid predictions' of the biological activity of chemicals. (Oser and Hall 1977, 464) Each of those claims deserves to be critically appraised.

\section{The usefulness of the FEMA panel approach}

The obvious sense in which the FEMA panel approach was 'far more useful' than having to commission toxicity or even metabolic studies on each flavour additive was that the food and flavouring industries did not have to bear the costs of those studies. FEMA executives had long complained about the costs of toxicological tests. In 1964, for example, Hall remarked that:

"[o]nly a handful of existing flavors enjoy commercial volume sufficient to have justified two year toxicity studies. It is almost inconceivable that a new flavor not yet tried on the market or accepted by industrial users would have such indications of potential commercial value as to encourage its sponsors to invest in a program of chronic toxicity tests." (Hall, 1964)

Another sense in which the FEMA panel approach was far more useful than conducting toxicological studies, at least from the perspective of the flavouring 
industry, was that the approach was extraordinarily permissive, both in relation to what was known and not known about predicting chemical toxicity, and in relation to a toxicity-test-based approach. It is worth re-emphasising that the FEMA panel approach rested on a set of key assumptions, many of which we have already been made explicit in the preceding discussion:

- Molecular structure provides a robust predictive basis for inferences about metabolism, by drawing on analogies with chemicals deemed to possess 'similar' structures whose metabolism is known.

- Known or assumed metabolism can in turn be used to licence inferences about toxicity, by analogy with chemicals of 'similar' structure that have been tested for short term effects

- For flavours with unknown metabolic fate, potential toxic effects can reliably be detected by 14-day toxicity tests on those compounds, and inferences can also be drawn from chemicals of 'similar' structure that have been tested in a long term study.

- $2 \mathrm{mg} /$ day is a safe level of exposure where chemical structure is assumed, by analogy, to imply familiar metabolic fate and an absence of toxicity.

Most of those assumptions were defended by the FEMA panel as 'reasonable', (e.g. Oser and Hall 1977, 460, 462 \& 463) but even then contrary assumptions could have been no less reasonable, and they were all highly optimistic, even from the point of view of FEMA's own expert advisors.

For example, the assumption that the toxicity of a flavour compound could reliably be estimated by drawing analogies from chemicals of 'similar' chemical structure for which some toxicity data existed depended on a level of understanding of the relationship between structure and toxicity that was just not available. The limitations in the predictive power of structure-activity modelling was even acknowledged 14 years later by two FEMA panel members, Woods and Doull, when they noted that: "[o]bviously, the current level of knowledge [of the relationship between chemical structure and toxicity] does not permit the precise prediction of the biologic effect of a new chemical." (Woods \& Doull 1991, 53)

Likewise, the FEMA panel assumed that the toxicity data on 'similar' chemicals from which analogies could be drawn need only consist of data from 14-day feeding studies. This implied that chronic and other toxic effects that could not be identified by 14-day feeding studies should not occur, at least at the doses to which people were exposed. Oser and Hall did not attempt to justify that further assumption (or even make it explicit). In 1991, however, FEMA panel members Woods and Doull did so. They explained that FEMA did not require tests for effects such as 'behavioural, genetic, immunological and reproductive toxicity' on the grounds that "[s]ince flavor ingredients are generally used in very small amounts, a few parts per million, it is 
unlikely that they will produce any of the above adverse effects" [emphasis added]. The permissive nature of that judgement is obvious. Although it served the interests of FEMA's members, it was not evidence based.

A third sense in which the FEMA panel approach was far more useful than toxicity testing, from the point of view of the flavouring industry, was that FEMA executives were anxious that toxicity studies produced false positive findings (i.e. studies that erroneously indicate that a compound is toxic). Consequently, articulating a narrative to justify conducting no toxicity tests was intended to minimise that risk. This was a fact that FEMA executives usually only made explicit in private. For example, an unpublished 1983 report for FEMA members argued that:

"Conventional toxicological testing - especially in its most complex and cumbersome form, the carcinogenicity test, has reached a scientifically dead end.... They are so complex they are error-prone, producing errant results or errors so obvious they require a repeat. In order to avoid missing something - a 'false negative' - they are purposely designed in ways that make the production of false positives inevitable... It is difficult to imagine circumstances that would lead us to recommend a 'conventional' carcinogenicity study." (Anon, 1983)

Another report for FEMA members, written by Hall three years later, is also splendidly revealing:

“...mutagenicity tests ... are, in our view, useful for experimental purposes. But they do not mesh with the results of carcinogenicity studies as well as their enthusiasts claim, and the interpretation of their results for human safety is uncertain. Choosing to run them on a substance of known value is a little like choosing to install a slightly loose cannon on the deck." (Hall, 1986)

Those comments reveal the extent of FEMA's reluctance to conduct any experiments that might raise questions about about the safety of its member's products, and it's insistence that any indication of possible toxicity must be misleading. They also imply that the toxicologically data-free approach FEMA advocated and adopted did not just happen to serve, but was knowingly intended by FEMA to serve, the interests of FEMA, it members and their commercial customers in the food processing industry.

Not surprisingly, the acceptance by the FDA of the FEMA panel's approach entailed that, in practice, very few flavouring substances were denied GRAS status by the FEMA panel on safety grounds. Although FEMA has not published a list of such flavourings, in 1986, a then member of the FEMA panel noted that, of the 1400 flavours that were re-reviewed by the FEMA panel between the 1970s and the mid1980s, only two were denied GRAS status on grounds of safety. (Ford, 1986) In both those cases, although Ford does not mention this, evidence of lack of safety derived 
not from analysis based on the FEMA panel's approach, but from conventional toxicity tests conducted by the public sector.

\section{The validity of the FEMA panel approach}

In 1977 Oser and Hall claimed that the panel's approach was able to make 'quite valid predictions'. That phrase is, however, interpreted with remarkable ambiguity in the community of professional toxicologists. Some toxicologists treat the results of studies on laboratory animals as the benchmark by reference to which other approaches and data sets should be judged. Occasionally, toxicologists talk as if the effects on humans, as revealed for example by epidemiological studies, can provide the only truly relevant benchmark. In both cases, judgements of 'validity' would be made by reference to evidence of putative effects, or lack of any effects, in some 'target' species. Oser and Hall's claim that the FEMA approach was 'valid' implied that its predictions would be consistent with empirical data, be they toxicological or epidemiological, were they to be available or to become available. But as the FEMA panel approach was not remotely evidence-based the suggestion that it was a scientifically valid approach was, and remains, misleading.

It was striking, even in 1977, that if there had been empirical support for the claims asserted or implied by the FEMA panel, Oser and Hall failed to acknowledge it. With one exception, their account of the panel's approach to assessing flavour safety made no reference whatever to supporting evidence, whether in the wider scientific literature or in any other form, when describing and justifying each and every one of the central elements of the panel's approach. For example, their claim that metabolism and toxicity can be inferred from data on structurally similar chemicals comprised a narrative assertion of that claim, but they provided no evidence that such inferences were valid. Similarly, the claim that there is a threshold intake level of 2 mg per day, below which no effects can occur, and the implicit assumption that chronic toxicity cannot occur at typical human exposure levels, were invoked as if they were self-evident. No justification was provided; it was little more than a rhetorical exercise of self-interested wishful-thinking

The one exception, as far as referring to some scientific literature was to a report published in 1969 by a 'Task Force' of the Food Protection Committee, a body operating under the auspices of the US National Academy of Sciences and US National Research Council. Oser and Hall cited that report as evidence of 'widely acknowledged' support for the claim that structure could be used to predict toxicity by analogy. That report, entitled 'Guidelines for estimating toxicologically insignificant levels of chemicals in food' had proposed that where organic chemicals that are intentionally added to food possessed structures that 'suggested' that they would be handled through known metabolic pathways, and where they were also members of a group of 'closely related' substances that were, or could be 'presumed' to be, low in 
toxicity, concentrations in the diet of less than 1 part per million could be deemed 'toxicologically insignificant' and, for regulatory purposes, ignored. (FPC, 1969) That document also cited no supporting evidence for its central claim; it just referred to a single endorsement in a paper written by one of the report's authors.

The identical logic, and similar language, to that used earlier by Hall and his FEMA colleagues in 1960, and in turn by the FEMA panel, in respect of food flavourings, was not entirely coincidental. The task force comprised nine scientists, five of whom were employed by the food or chemical industries, (Washington Post, 1971) including both Hall and Oser. The Food Protection Committee, which convened the task force, had been set up and funded by the food industry in 1950 after Congress had started to debate amendments to the existing body of food safety regulations. (Mulford, 1958)

On publication the task force report attracted substantial criticism. An expert committee established by the Surgeon General argued that the task force's key claim that substances could be considered safe without undergoing biological assay, was 'scientifically unacceptable', and that the task force had displayed a '...lack of understanding and appreciation of factors involved in chronic toxicity ..' (USPHS, 1970) In response Oser and Ford (1977) explained that an ad hoc group was created by the National Academy of Sciences to 'clarify' the task force's report. The ad hoc group reinterpreted the report and tried to portray it as not having been intended to suggest that a chemical could be deemed safe in the absence of experimental data, or that testing was not needed, but rather to suggest criteria for determining priorities for testing. (Oser \& Ford, 1977, 65-66) Furthermore, they tried to rebut the suggestion that the report's recommendation served to deter scientific investigation, arguing that '...schemes for setting testing priorities for specific purposes (particularly long term toxicity) must be encouraged'. (Oser \& Ford, 1977, 66)

On that occasion the attempt by the US food industry to exempt all its food additives, used below certain concentrations, from any toxicological testing was a failure. Yet, the FEMA panel had managed to establish such a data-light, and empirically unsupported, self-regulatory scheme for flavourings. Moreover that scheme bore a striking resemblance to the 'un-clarified' version of the task force report.

\section{Early regulatory responses to the flavouring industry's approach}

In the USA, as already noted, the Food and Drug Administration (FDA) treated all of the flavourings on the FEMA panel's GRAS lists as acceptable for unrestricted use in processed foodstuffs from the outset. Yet the FEMA panel's general approach was never fully sanctioned by the FDA. As an FDA employee explained in 1991:

"The FDA has not decided on the legality of many of the substances on the FEMA GRAS list ... but has informally acknowledged that [their use] ... would not be 
objectionable until the FDA has fully evaluated their safety. In fact, the FDA has considered this evaluation low priority in comparison with other food ingredients, primarily because of the low consumer exposure to flavours in general" (Lin 1991, 882)

In other words the FDA did not formally endorse the approach adopted by FEMA but decided that there were more important issues to which to direct its resources.

In other countries, the flavouring industry tried to argue that a similar approach to that advocated by FEMA in the USA should also be adopted. Yet, as one observer noted in 1969, the US approach had been "... severely criticized by European regulatory officials and toxicologists. It has not yet been adopted by any international organization or in any proposed changes to national statutes and regulations in Europe.” (Barton Hutt 1969, 33)

In the UK, for example, the government had proposed in the early 1960s that a permitted list of flavours should be established, and in order to do so had asked the flavouring and food industries to submit "...evidence as to the absence of any deleterious effect resulting from [flavour] use..." (FSC 1965, 3) In response, the industry argued that because flavouring agents had been used in food for many years without giving rise to complaint or illness they could be assumed to be harmless. In 1965 the relevant UK expert advisory committee responded as follows:

"We cannot however accept the trade's view that long usage and no apparent ill effects are sufficient evidence to demonstrate that a substance is harmless in the absence of satisfactory toxicological data. We were presented with very long lists... of both natural and artificial flavourings without any corresponding scientific data on the pharmacological aspects or toxicity of these substances... [We] were somewhat disturbed that there was really no toxicity data on most flavouring agents... We strongly urge manufacturers not to introduce new flavourings unless assured of their safety ...." (FSC 1965, 67)

The food and flavouring industry were again asked by the UK government to provide experimental data on flavourings, for an assessment within five years. But a decade later, in 1976, the UK's expert committee reported that the industry had continued to fail to provide any evidence. (FACC, 1976) UK regulators could have refused to allow the food industry to use flavours until after adequate toxicity data had been provided, but they did not do so. As a consequence, except for a handful of substances that were prohibited, flavours in the UK remained unregulated.

Within the framework of the then European Community, discussions about a harmonised approach for regulating flavours began in 1967, (CEC, 1979) although legislation to enable harmonised control was not published for another twenty years. 
In the meantime the European Commission's Scientific Committee for Food (SCF) made clear that it expected the Commission to regulate flavours in the same way as other food additives. In 1981 for example, in relation to a Commission proposal to permit the use of all natural flavours and synthesised equivalents of natural flavours unless expressly prohibited, it stated that:

"The Committee reiterates the statement in its $10^{\text {th }}$ report that before an additive is accepted for use in food it should have been subjected to an adequate toxicological evaluation, and sees no reason, on the information available to it about flavourings to depart from this principle. A system which proposes that a substance or material could be used in food without evaluation until proof of danger would not be compatible with the Committee's interpretation of what was needed to protect public health. The fact that a substance occurs in food or has been synthesised to be identical to a substance occurring naturally in food is no proof of its inherent safety." (CEC 1982, 11)

At an international level, the Codex Alimentarius Commission, an institution created in 1962 by the World Health Organisation and Food and Agriculture Organisation to set standards for internationally traded foodstuffs, also began to take an interest in the safety of flavourings. In 1967, the Codex's Joint Expert Committee on Food Additives (JECFA) explained that although it had not previously considered flavourings

"[i]t has, however, become increasingly obvious that toxicological hazards might arise from certain diets if high levels of some of these flavouring substances were used. Some flavouring substances of natural origin that were previously considered innocuous are now known, as a result of animal experiments and more modern investigations, to be toxic.... Certain other flavouring substances ... when ingested in minute amounts, have been shown to induce hypersensitive reactions. In addition, some flavouring substances are consumed in large amounts by children." (WHO 1968, 6)

JECFA conducted its first toxicological evaluation of a small number of flavouring compounds in that year. Present, on that occasion, as members of JECFA and its Secretariat, respectively, were FEMA's Richard Hall and Bernard Oser. (WHO 1968) Despite the 'strong objection' of Hall and Oser, (Barton Hutt 1969, 34) JECFA proposed adopting its normal toxicological-based approach to evaluate the flavourings, and it set toxicity-based maximum intake levels for 11 flavouring compounds. This was, however, the last occasion for many years that JECFA did so. As a prominent US food lawyer recalled: "As a result of vehement U.S. objection to this [toxicological] approach ...the [Codex] Commission has now withdrawn from its leadership role in this area..." (Barton Hutt, 1969, 34) 
JECFA returned on a few occasions during the 1970s and 1980s to evaluate flavours, again insisting on a toxicity-data driven approach, but it set standards for only about one new compound per year. The problem was that the flavouring industry had produced very little toxicity data on its flavour compounds. By the beginning of the 1990s, JECFA had tried to set standards for about 400 flavours but had not been able to do so, mainly because of inadequate toxicity data. The Codex Committee on Food Additives had then avoided perturbing the commercial status quo by classifying those substances as 'temporarily acceptable'.

\section{Persuading Codex}

In the run up to the creation of the single European market in 1992, and especially the creation of the World Trade Organisation in 1995 which designated Codex standards as the benchmark for global harmonisation, the flavouring industry began to argue strongly for a common global approach. (Grundschober, 1995) What the industry wanted, and what it eventually obtained, was a common system based on the FEMA panel approach.

JECFA had, on various occasions since the late 1960s, argued that a system for determining priorities for testing flavours was desirable but it had always insisted that a toxicological evaluation of flavours would nonetheless be necessary. In1987, however, a WHO task group (comprising the members of JECFA and a secretariat of 33 individuals, which included several food industry representatives and consultants) issued a report that marked the beginning of a shift from that position. It argued that "[i]n view of the very large number of substances used as food flavouring .. it is considered impractical and unreasonable to require that each food flavouring material be subjected to the same and extensive toxicological evaluation within a reasonable period." (WHO 1987, Sec. 6.1.2) Instead, it argued for a new system to set priorities for the testing of flavours, and for determining the extent of the testing to be required. (WHO 1987, Sec. 6.1.2)

There may have been several reasons why JECFA had begun to back down from its earlier stance, but the fact that for decades the flavouring industry had produced almost no toxicological data on thousands of substances was almost certainly one of the reasons why JECFA agreed that it was 'impractical' and 'unreasonable' to continue insisting on conventional toxicological evaluations.

Later in 1987, five of the US representatives at Codex, comprising four FEMA members and an official from the US FDA, submitted a proposal for the kind of 'prioritisation' system recommended by the WHO Task Force. (Rulis et al, 1987) The proposal involved allocating the group of 400 or so flavours that JECFA had previously tried to evaluate but had listed as 'temporarily acceptable' (because sufficient toxicity data had not been provided by the industry) into six categories. The 
categories were based on the kinds of information used by the FEMA panel to evaluate flavours, namely estimated human exposure levels, chemical structures, and natural occurrence in food, as well as any available toxicity data. The proposal was that toxicity-based evaluations by JECFA should focus on compounds in the highest categories (to which fewer than two dozen of the 400 compounds were allocated) whilst substances in lower priority classes could continue to be used with minimal presumed risk until such time as in depth examination was possible. Nevertheless, a phrase added to the end of the FEMA/FDA proposal noted that:

"The [Codex] Committee may well come to the conclusion that 'The JECFA has reviewed the status of hybrid priority levels four to zero, and has concluded that the substances in these levels are currently in an appropriate priority category and that the existing data indicate no objections to current usage reported to the Committee that would merit a change in this priority status."” (Rulis et al. 1987, 10)

This final remark was in effect suggesting that flavours allocated to levels 4 and below (some 370 compounds) should be exempted from any future evaluation. It also appeared to be prejudging JECFA's judgement before that committee could have considered the proposal.

JECFA adopted FEMA's prioritisation scheme and within a few years it had indeed abandoned the toxicological data-based approach to setting acceptable daily intakes, though not just for lower ranking flavours, but for all flavours. This marked change in its evaluation strategy began at a JECFA meeting in 1995 when one of the scientists on JECFA, Ian Munro (1996), proposed that his committee adopt a modified version of the approach used by the FEMA panel. Munro was also a member of the FEMA panel in the USA, and his proposal for JECFA had been commissioned by FEMA. (Munro et al, undated)

Munro's modification was to invoke a concept, which he termed a 'threshold exposure value' for each of the three so-called structural classes used within the FEMA panel approach. Those values were derived from a data-base of 'no observed effect levels' (NOELs) from sub-chronic and/or chronic feeding studies (but not carcinogenicity or genotoxicity studies) on 612 organic chemicals, largely nonflavouring substances. NOELs are generally defined as the lowest dose level in a toxicity study at which there is no statistically significant increase in the adverse effects that are examined, compared to controls. Munro allocated the 612 compounds to the three FEMA panel structural classes, and plotted the NOELs in each class in cumulative distributions. The 5th percentile of the distributions of NOELs for each structural class was then converted using a scaling protocol into a so-called 'threshold exposure value'. 
Munro (1996) proposed that, where estimated intakes of flavours were below that threshold value for its class, JECFA should consider them to be safe, so long as the flavours could be 'expected' to be metabolised to innocuous products, or alternatively a NOEL on a structurally-related chemical was at least 10 times higher than the fifth percentile of NOELs in the wider database for the relevant class.

Where estimated intakes of a flavour were above the threshold value for its class, Munro proposed that it could be considered safe so long as the flavour could be 'expected' to be metabolised to innocuous products and either the substance or its metabolites were endogenous, or a NOEL on a structurally related substance was 'high enough to accommodate any perceived difference in toxicity between the flavour and the structurally related substance'. In circumstances where metabolism to innocuous substances could not be predicted, Munro argued that toxicity data would be needed 'on the substance or very closely related substances' to perform a safety evaluation'.

Munroe's proposal reproduced the FEMA panel's reasoning that the toxicity of a compound could be assumed from its structure and predicted metabolic fate or inferred from data on structurally similar compounds. The main difference was that instead of the $2 \mathrm{mg}$ /day exposure threshold that the FEMA panel had claimed could be used to classify flavours as GRAS that were presumed to metabolise to innocuous products, the 'threshold' became $1.8 \mathrm{mg} /$ day and $0.54 \mathrm{mg}$ /day for Class 1 and II substances; figures that were based on the estimated level of exposure that had not given rise to certain (limited) kinds of adverse effects in 95\% of a larger group of chemicals. Yet, even where the estimated intake of a candidate flavouring compound exceeded those thresholds, Munro still argued that judgements about safety could be inferred from toxicity data on related substances. As with the FEMA panel approach, there were very few circumstances in which the flavouring industry might be required to generate toxicity data on a candidate compound.

Another important difference was that Munro emphasised that his evaluation scheme was not intended to apply to chemicals that had unresolved toxicity problems or were 'presumed or known carcinogens'. But since his scheme did not, in most circumstances, require any toxicological data on candidate compounds, and certainly no carcinogenicity or genotoxicity data, it was entirely unclear how such exceptions could ever be identified.

In 1997 JECFA endorsed Munro's proposed scheme and began to assess flavours within chemical groups, requiring little or nothing in the way of toxicological data. (WHO, 1997)

\section{Enrolling the European Commission}


Within the European Union/Community, the first significant step towards a harmonized approach to the regulation of flavouring substances began in 1991 when a working group of the European Commission's Scientific Committee on Food published a guidance note on how it planned to assess flavours under a then proposed European-wide flavourings Directive. (SCF, 1991)

The working group began by emphasising that it wished to reiterate earlier statements by the SCF that flavourings should be subject to an adequate toxicological evaluation before being accepted for use in food. (SCF 1991, 22) Yet, the working party went on to argue that the sheer number of flavours, and the fact that most of them had not been subject to toxicological testing, meant that the kinds of procedures used for other food additives "...would not lead to a useful outcome within a reasonable time scale." (SCF 1991, 23) Thus, as with the WHO Task Force a few years earlier, the fact that the flavouring industry had for years generated such little toxicity data was one of the reasons why the SCF were backing away from their previous commitment to an adequate toxicological evaluation.

Instead the working group suggested what it characterised as "...a more pragmatic and flexible approach..." that would make use of estimates of levels of use in foods, potential daily intakes, structure-activity relations, anticipated metabolic fate, natural occurrence in food, (i.e. the same criteria as the FEMA panel) as well as some toxicological data. As far as the latter were concerned, the working group stated that: "... at least information on sub-acute (28 day) toxicity or sub-chronic (90 day) oral toxicity as well as data on mutagenicity, are needed for evaluation." (SCF, 1991, 26)

Those modest proposals for toxicological data provoked serious concern within FEMA. (Appleton, 1993) One reason for that anxiety was because they would undermine FEMA's entirely non-toxicological data-driven rational for supposing that flavours are safe. For example, in October 1993, a tobacco industry participant at a FEMA meeting noted that the Council of Europe (which had issued proposals for setting flavouring standards since the 1970s and whose expert advisors on flavours were also on the SCF working group) was updating requirements for dossiers on natural flavourings. Those revised requirements had indicated that, as with the SCF working group, data from 28-90 day toxicity studies would be needed. The participant noted that:

"FEMA has taken the position (to date) that it will not agree to any of these studies since agreement would call into question the meaning of GRAS status. Potential problem - FEMA has no formalized method to point to concerning evaluation of [natural flavours]. Many (if not all) were just grandfathered in." (Swauger, 1993)

That comment confirms that FEMA and its members had not just failed to provide data required for toxicological assessments; they had collectively decided that such 
data would not be provided, to prevent any such assessments from being conducted. FEMA's strategy was therefore anti-scientific as it constituted a policy of refusing to conduct potentially informative studies.

Some flavouring industry executives expected that the fact that the industry had never provided much in the way of toxicological data would force European regulators to drop its insistence on toxicity studies and sanction a version of FEMA's data-free approach to assessment, if it was ever going to compile a list of acceptable flavours. As the Scientific Director of the International Organisation of the Flavour Industry explained to colleagues in December 1993:

Several attempts have been made in the past to quantify toxicological insignificant exposure. ... Unfortunately toxicologists are not prepared to accept such a proposal, especially if made by the industry. As it [FEMA's priority scheme for JECFA with a proposal to accept all low priority flavours without testing] was based on sound scientific notions, it may be possible that toxicologists reach a similar conclusion, if confronted with the task of evaluating large numbers of flavouring substances of low risk. The Flavour Working Group [of the SCF] will have great difficulty terminating the stepwise elaboration of the proposed list unless it develops some evaluation criteria based on exposure and toxicological insignificance. In this event, industry may be able to gain approval of new substances just by providing exposure information.” (Grundschober, 1993)

In any case, the European flavour industry lobbied hard to get the SCF working party's toxicity testing requirements dropped entirely. (van Berge, 1993) By March 1996, the International Organisation of the Flavour Industry told its members that the European Commission intended to revise the 1991 SCF working group Guidelines through a procedure in which industry's interests would be formally represented: “A small group of scientists and regulators will be set up to re-examine those Guidelines which, if modified, will have to be approved by the SCF. The Group will include representatives from the SCF, the Commission, the [Council of Europe], the US FDA as well as the European and the US flavour industry." (Anon, 1996)

We have not been able to discover the outcome of that re-examination, or the extent to which revised guidelines were adopted by the SCF. Nevertheless, in December 1999, the SCF published a 'further opinion' on how flavours would be evaluated. This revealed that the SCF was concerned that the Munro/FEMA approach, which had recently been sanctioned by JECFA, did not address the potential genotoxicity of flavours and 'did not take into account possible toxic effects that may occur at low doses such as neurological, immunological, endocrine and developmental effects.' (SCF 1999, 7) Nevertheless, he committee announced that it henceforth intended to use the Munro/FEMA scheme within the evaluation programme of the Commission. (SCF 1999, 6-7) 
Three years later, the SCF began constructing a list of permitted flavours using the Munro/FEMA approach. The requirement, a decade earlier, that at the very least data from 28 or 90 day feeding studies and mutagenicity studies would be required, had been dropped.

\section{Conclusions}

Our analysis of the development of the principles and methods for assessing the safety of flavouring additives, adopted by regulatory institutions worldwide, has shown that they were constructed by and for the flavourings industry, and have served its (confidentially) explicit agenda of minimising the costs of complying with regulatory oversight, and of ensuring that there is as little risk as possible that the market for its products might be restricted. This was accomplished by constructing an approach to appraisal in which only homeopathic quantities of data were required, and a set of criteria for judging the acceptability of flavours that were conspicuously permissive, relative to both our knowledge (and lack of it) about chemical toxicity, and to the ways other kinds of chemicals are regulated. The approach also served to discourage scientific investigation of important aspects of the phenomena it purported to evaluate, and relied on underlying knowledge claims that were assertions and hypotheses that lacked any evidential basis. In those respects, the approach was both unscientific and anti-scientific, a consequence of which is that the quality and extent of our knowledge of flavouring toxicity and safety is far more fragile than it otherwise might be.

The approach was first sketched out by a small group of flavouring industry scientists in the early 1960s. The US flavourings industry, as embodied in its trade association FEMA, was allowed to set up its own self-regulatory regime, in which those methods and procedures were adopted, and only marginally modified, by a small group of scientists working for or on behalf of the flavouring industry. In effect, FEMA not only acted as its own judge and jury, it also chose which 'charges' it might face, and even wrote the rules, because it both defined how much of which kinds of evidence would be sufficient for the regulatory regime in which it chose to cloak its activities as well as the criteria by which that evidence would be judged.

FEMA's approach eventually prevailed in much wider regulatory circles, despite its initial but sustained rejection on the part of scientific advisors to UK, European and international regulators. We have documented processes of lobbying, the involvement of flavouring industry employees and FEMA panel members on JECFA and its secretariat, and adjustments to and elaborations of the FEMA panel approach, as part of the process whereby the flavouring industry persuaded regulators and their advisors outside the USA to sanction and adopt the FEMA approach. We have not been able to identify all the mechanisms, and underlying reasons, contributing to those decisions 
but, amongst those that we have documented, the collective resolute refusal of FEMA's member companies, over three decades, to provide the toxicological data which were requested by expert advisors, and upon which a more conventional approach could have been put into practice was a key reason. The flavourings industry called the regulators' bluff, and the regulators effectively surrendered rather than disturb the status quo.

Industry control over the supply and interpretation of knowledge and expertise is widely recognised as one mechanism by which regulatory capture sometimes occurs. Whilst our account supports that general thesis, we have highlighted how variants of that mechanism (and that to the best of our knowledge have not previously been documented in the regulation literature) contributed to capture. Specifically, it was initially the failure of industry to provide relevant knowledge, rather than (as most of the literature emphasises) control over its production and interpretation, that initially gave rise, outside of the USA, to regulatory capture - in the sense that regulatory agencies were not subsequently able to make decisions in ways that they considered appropriate and so flavourings remained effectively unregulated. Furthermore, once the flavouring industry decided that its products ought to be regulated, in Europe and internationally, in the run up to the creation of a European single market and the WTO, capture, capture was not so much (or not just) a matter of industry control over the provision and interpretation of regulatory knowledge, but rather a case of the industry creating its own analytical assessment framework, to avoid regulatory costs and restrictions, and then persuading policy-makers to adopt and internalize that framework, the consequence of which is that industrial interests and values have become woven into the regulatory culture of flavouring safety assessment.

Our critical analysis of the discourses of science and regulation has documented the main features of the process by which the flavourings industry designed and constructed its own preferred regulatory regime and then persuaded the authorities in several major industrialised jurisdictions to adopt and implement it. Our account supports empirical conclusions about the deployment of scientific narratives in the construction of this regulatory regime. Given however that our account also shows that the process of constructing statutory regimes of regulation was accomplished in spite of a conspicuous lack of empirical support for those narratives, our account supports a normative critique of the resulting regimes.

The resulting regime is one that is routinely portrayed as if legitimated by science, but we have shown that it could more accurately be characterised as unscientific, pseudoscientific and anti-scientific. It is unscientific because it is constructed from a complacent and reassuring set of hypotheses that are almost entirely unsupported by empirical data, while masquerading as if soundly scientific. To the extent that it is self-interested wishful thinking masquerading as if sound science, it is ipso facto pseudo-scientific. To the extent that the regime has been constructed on a refusal to conduct tests or gather potentially illuminating data it has served to prevent the 
advance of bio-chemical and toxicological knowledge. We will never know much about what risks consumers may have been taking by ingesting flavouring additives until the regulatory regime covering flavouring additives has been significantly strengthened. There is some evidence, mostly from studies conducted independently of the flavourings industry that some flavourings currently deemed officially acceptable may pose risks to human consumers, but that is the topic for a subsequent paper.

In this context it may be sufficient to note that our empirical and normative critique of the construction of the regulatory regime covering flavourings resonates with our 'realist constructivist' account of how the techniques of the sociology of regulatory science can serve not just to describe and explain outcomes, but also support empirically well-informed judgements about the relative credibility of competing scientific claims about, in this case, the safety of food flavouring additives. (van Zwanenberg \& Millstone, 2000) Sociological deconstructions of regulatory science frequently document how industrial interests and values shape regulatory scientific claims. Our account too has shown that commercial interests in the avoidance of regulatory costs and restrictions were absolutely pivotal to the development of the flavouring industry's scientific narrative about how to assess flavouring safety. Yet, given the choice-laden nature of science, such findings do not themselves imply that such narratives are necessarily unscientific or unreliable, (cf Sismondo 2009).Our account has shown that the additional step of scrutinising the extent to which such narratives adhere to very widely accepted scientific norms - in this case the norm that scientific claims require some as opposed to no empirical support - can be highly informative and relatively straightforward. The resolutely reassuring narrative consistently articulated by FEMA and its corporate allies, has been shown to be a fragile and shoddy construction, incorporating only homeopathic doses of empirical data, and vast swathes of optimistic wishful thinking. We have therefore provided robust grounds for concluding that the regulatory regime covering flavourings should be significantly strengthened.

\section{Bibliography}

Abraham, J. (1993) Scientific Standards and Institutional Interests: Carcinogenic Risk Assessment of Benoxaprofen in the UK and US, Social Studies of Science, Vol. 23, pp. 387-444

Abraham, J. \& Ballinger, R. (2012) Science, politics, and health in the brave new world of pharmaceutical carcinogenic risk assessment: Technical progress or cycle of regulatory capture? Social Science \& Medicine, vol. 75, pp. 1433-1440. 
Anon (1983) Flavor and Extract Manufacturers' Association Safety Evaluation

Coordination Committee, Annual Report, April 22, 1983, available at:

$<$ http://legacy.library.ucsf.edu/tid/yyd98c00/pdf $>$

Anon (1996), 79th meeting of the IOFI committee of experts and meeting of the EFFA flavour experts, Memo dated March 26, 1996, available at:

$<$ http://legacy.library.ucsf.edu/tid/dwt03c00/pdf $>$

Appleton, S. (1993) Memo dated March 6, 1993, Flavor and Extract Manufacturers' Association (FEMA) Meeting, available at:

$<$ http://legacy.library.ucsf.edu/tid/gaq51f00/pdf $>$

Ashford, N. A. et al (1983) A Hard Look at Federal Regulation of Formaldehyde: A Departure from Reasoned Decision-making, Harvard Environmental Law Review, Vol. 7, pp. 297-370

Barton Hutt, P. (1969) Developments in international regulation of flavouring substances. American Perfumer and Cosmetics, Vol. 84, pp. 33-35, available at $<$ http://legacy.library.ucsf.edu/tid/kkm97a99/pdf $>$

Bloor, D. (1976) Knowledge and social imagery. (Routledge \& Kegan Paul: London)

Castleman, B.I. \& Ziem, G.E. (1988) Corporate influence on threshold limit values, American Journal of Industrial Medicine, Vol. 13, pp. 531-559

CEC (1979) Reports of the Scientific Committee for Food, Ninth Series, (Luxembourg: Commission of the European Communities)

CEC (1982) Reports of the Scientific Committee for Food, Thirteenth Series, Commission of the European Communities, Luxembourg

CEC (2008) Regulation No 1334/2008 of the European Parliament and of the Council of 16 December 2008 on flavourings and certain food ingredients with flavouring properties for use in and on foods. Commission of the European Communities, Luxembourg

Degnan, F.H. (1991) Rethinking the Applicability and Usefulness of the GRAS Concept, Food, Drug, Cosmetic Law Journal, vol. 46, pp. 553-582

Emerson, J. L. (1990) Report of the Safety Evaluation and Coordination Committee, dated 05/01/90, available at: $<$ http://legacy.library.ucsf.edu/tid/zqh14d00/pdf $>$ 
Ford, R. (1986) 'The function of expert panels in evaluating the safety of flavouring and fragrance materials', paper to Essential Oils, Fragrance \& Flavors $10^{\text {th }}$ International Congress, $1986,4^{\text {th }}$ Session, $\mathrm{p}$ 71-72.

FACC (1976) Report on the Review of Flavourings in Food, Report 22, (HMSO: London)

FPC (1969) Guidelines for estimating toxicologically insignificant levels of chemicals in food, (NAS/NRC: Washington D.C.)

FSC (1965), Report on Flavouring Agents, Ministry of Agriculture Fisheries and Food, HMSO, London.

Gillespie, B. et al (1979) 'Carcinogenic Risk Assessment in the United States and Great Britain: The Case of Aldrin/Dieldrin', Social Studies of Science, Vol. 9, pp. 265-301

Grundschober, F. (1993) Memorandum on the proposed EC Flavour Regulation, dated 22/12/1993, available at <http://legacy.library.ucsf.edu/tid/oci17a99/pdf >

Grundschober, F. (1995) 'The role and activities of IOFI - A need for harmonization of flavour regulations'. October 5, 1995, Brussels, available at:

$<$ http://legacy.library.ucsf.edu/tid/amk40d00/pdf $>$

Hall, R. L. (1960a) Flavor Additives and the Food-Additives Amendment, Food, Drug, Cosmetic Law Journal, Vol. 15, pp. 24-36

Hall, R. L. (1960b) Recent Progress in the Consideration of Flavoring Ingredients Under the Food Additives Amendment, Food Technology October 1960, pp. 488-495

Hall, R. L. (1964) 'Report of the FEMA Food Additives Committee', Food Drug Cosmetic Journal, Vol. 19, pp. 612-19

Hall, R. L. (1986) 'Report of FEMA's Safety Evaluation Coordination Committee', available at $<$ http://legacy.library.ucsf.edu/tid/lto15d00/pdf $>$

Hall, R. L. \& Oser, B. (1961) Recent Progress in the Consideration of Flavoring Ingredients Under the Food Additives Amendment II, Food Technology, Vol. 15, pp. 21-26

Hall, R. L. \& Oser, B. (1965) Recent Progress in the Consideration of Flavoring Ingredients Under the Food Additives Amendment III, Food Technology, Vol. 19, pp. 151-197 
Hall, R. L. \& Oser, B. (1968) The safety of flavoring substances, Residue Reviews, Vol. 24, pp. 1-17

Hallagan, J. B. \& Hall, R. L. (1995) 'FEMA GRAS - A GRAS Assessment Program for Flavor Ingredients', Regulatory Toxicology and Pharmacology, Vol. 21, pp. 42230 .

Huff, J. (2002) IARC Monographs, Industry Influence, and Upgrading, Downgrading, and Under-grading Chemicals, International Journal of Occupational and Environmental Health, Vol. 8, pp. 249-270

Jasanoff, S. (1987) 'Cultural Aspects of Risk Assessment in Britain and the United States, in B. B. Johnson \& V. T. Covello (eds) The Social and Cultural Construction of Risk: Essays on Risk Selection and Perception, D. Reidel, Dordrecht \& Boston, pp. 359-397

Jasanoff, S. and Wynne, B. (1998) 'Science and Decision-Making', in Rayner, S. and Malone, E. L. (eds) Human Choices and Climate Change: Volume 1 - The Societal Framework, Ohio: Battelle Press

Latin, H. (1988) 'Good Science, Bad Regulation, and Toxic Risk Assessment', Yale Journal on Regulation, Vol. 5, pp. 89-148

Lehman, A.J. et al (1955) Procedures for the Appraisal of the Toxicity of Chemicals in Foods, Drugs and Cosmetics, Food Drug Cosmetic Law Journal, Vol. 10, pp. 679747

Lewis, R.J. (1989) Food Additives Handbook (Chapman \& Hall: New York)

Lin, L. J. (1991) 'Interpretation of GRAS Criteria', Food, Drug, Cosmetic Law Journal no. 46 , pp. $877-884$

Michaels, D. (2008) Doubt is their product: How industry's assault on science threatens your health, (Oxford University Press: New York)

Mitnick, B. M. (2011) Capturing 'Capture': Definition and Mechanisms, in D. LeviFaur (ed) Handbook on the Politics of Regulation, pp. 34-49 (Edward Elgar:

Cheltenham)

Mulford, K.E. (1958) The food additives committee of the Manufacturing Chemists Association, Food Drug Cosmetics Law Journal, Vol. 13, pp. 761-64

Munro, I.C. (1996) 'A Procedure for the Safety Evaluation of Flavouring Substances', WHO Food Additives Series 35, 1996, Annex 5, pp 423-459 
Munro, I.C., Kennepohl, H. \& Ford, R.A. (undated) Concept Paper for

Toxicologically Insignificant Exposure Criteria for Flavor Ingredients, available at: $<$ http://legacy.library.ucsf.edu/tid/tir04a99/pdf>

Oser, B. L. (1957), Food Additives Legislation Drags On, Food, Drug, Cosmetics Law Journal, Vol. 12, pp. 199-208

Oser, B. L. \& Ford, R. A. (1991) FEMA Expert Panel: 30 Years of Safety Evaluation for the Flavor Industry. Food Technology, November 1991, pp. 84-97

Oser, B.L. \& Ford, R.A. (1977) 'Recent Progress in the Consideration of Flavoring Ingredients Under the Food Additives Amendment 10. GRAS Substances' Food Technology, pp 65-74

Oser, B. L. \& Hall, R. L. (1977) 'Criteria employed by the expert panel of FEMA for the GRAS evaluation of flavoring substances', Food and Cosmetic Toxicology, 1977, Vol. 15, pp. 457-466

Rulis, A.M., Hall, R.L., Ford, R.A., Stofberg, J., and Easterday, O.D. (1987) A Codex Flavor Priority Ranking System, available at:

$<$ http://legacy.library.ucsf.edu/tid/ojx63d00/pdf $>$

SCF (1991) Guidelines for the evaluation of flavourings for use in foodstuffs:

Chemically defined flavouring substances. Reports of the Scientific Committee on Food, 29th Series, EC, Luxembourg,

SCF (1999) Opinion on a programme for the evaluation of flavouring substances, Scientific Committee on Food. (Brussels: EC)

Shackley, S. \& Wynne, B. (1995) Global climate change: the mutual construction of an emergent science-policy domain, Science and Public Policy, Vol. 22, pp. 218-230

Shapiro, S. (2012) The Complexity of Regulatory Capture: Diagnosis, Causality and Remediation, Roger Williams University Law Review, Vol. 102, No. 1, pp. 101-137

Sismondo, S. (2008) How pharmaceutical industry funding affects trial outcomes: Causal structures and responses, Social Science \& Medicine, Vol. 66, pp. 1909-1914

Sismondo, S. (2009) Ghosts in the machine: Publication planning in the medical sciences. Social Studies of Science, Vol. 39, pp. 171-198.

Smith, R.L., Cohen, S.M., Doull, J., Feron, V.J., Goodman, J.I., Marnett, L.J., Munro, I.C., Protoghese, P.S., Waddell, W.J., Wagner, B.M., Adams, T.B. (2005) Criteria for 
safety evaluation of flavoring substances. Food and Chemical Toxicology, Vol. 43, pp. 1141-1177.

Stirling, A. (2008) “Opening Up" and "Closing Down": Power, Participation, and Pluralism in the Social Appraisal of Technology, Science, Technology, \& Human Values, Vol. 33, pp. 262-294

Swauger, J. E. (1993) Trip Report - FEMA International Regulatory Affairs Committee Meeting October 5, 1993, Memo dated October 11, 1993, available at: http://legacy.library.ucsf.edu/tid/tys75a00/pdf

USPHS (1970) Evaluation of Environmental Carcinogens: Report to the Surgeon General, United States Pubic Heath Service, April 22, 1970, available at http://legacy.library.ucsf.edu/tid/qam87h00/pdf

van Berge, P. (1993) Speech at IOFI annual meeting, Geneva October 13, 1993, available at: http://legacy.library.ucsf.edu/tid/jys $75 \mathrm{a} 00 / \mathrm{pdf}$

van Dijk, T.A. (1993) Principles of critical discourse analysis', Discourse and Society, Vol. 4, No. 2 pp 249-283

van Zwanenberg P. \& Millstone E., 2000 'Beyond sceptical relativism: evaluating the social constructions of expert risk assessments', Science, Technology \& Human Values, Vol. 25, pp. 259-282

Washington Post (1971) US Debates Acceptable Cancer Risk, 21/12/71, available at: $<$ http://legacy.library.ucsf.edu/tid/xfl75b00>

WHO (1968) Specifications for the identity and purity of food additives and their toxicological evaluation: Some flavouring substances and non-nutritive sweetening agents. Eleventh Report of the Joint WHO/FAO Expert Committee on Food Additives, World Health Organization Technical Report Series No. 383. Geneva

WHO (1987) Principles for the Safety Assessment of Food Additives and Contaminants in Food. Environmental Health Criteria No.70. World Health Organisation, Geneva

WHO (1997) Evaluation of certain food additives and contaminants. Forty-sixth report of the Joint FAO/WHO Expert Committee on Food Additives). WHO Technical Report Series, No. 868, Geneva

Wickson, F. \& Wynne, B. (2012): Ethics of Science for Policy in the Environmental Governance of Biotechnology: MON810 Maize in Europe, Ethics, Policy \& Environment, 15:3, 321-340 
Woods, L.A. \& Doull, J. (1991) 'GRAS Evaluation of Flavoring Substances by the Expert Panel of FEMA' Regulatory Toxicology and Pharmacology, Vol. 14, pp. 4858

Wynne, B. (1992), "Uncertainty and environmental learning: reconceiving science and policy in the preventive paradigm", Global Environmental Change, Vol. 2, pp 111-127.

Zeltner, T., Kessler, D., Martiny, A., Randerer, F., 2000, Tobacco Industry Strategies to Undermine Tobacco Control Activities at the World Health Organization, Report of the Committee of Experts on Tobacco Industry Documents, Geneva: World Health Organization 


\section{Recent papers in the SPRU Working Paper Series:}

SWPS 2014-04. Alex Coad, Gabriele Pellegrino and Maria Savona. March 2014. "Don't Stop Me Now: Barriers to innovation and firm productivity."

SWPS 2014-05. Antonio Messeni Petruzzelli, Vito Albino, and Daniele Rotolo. April 2014. "Determinants of Patent Citations in Biotechnology: An Analysis of Patent Influence Across the Industrial and Organizational Boundaries."

SWPS 2014-06. Andy Stirling. April 2014. "From Sustainability to Transformation: Dynamics and diversity in reflexive governance of vulnerability."

SWPS 2014-07. Ralitsa Petrova Hiteva and Tomas Maltby. April 2014. "Standing in the way by standing in the middle: the case of state-owned natural gas intermediaries in Bulgaria."

SWPS 2014-08. Sabine Hielscher and Adrian Smith. May 2014. "Community-based digital fabrication workshops: A review of the research literature."

SWPS 2014-09. José García-Quevedo, Gabriele Pellegrino and Maria Savona. May 2014. "Reviving demand-pull perspectives: The effect of demand uncertainty and stagnancy on R\&D strategy."

SWPS 2014-10. Daniele Rotolo, Ismael Rafols, Michael Hopkins, and Loet Leydesdorff. June 2014. "Scientometric Mapping as a Strategic Intelligence Tool for the Governance of Emerging Technologies."

SWPS 2014-11. Andy Stirling and Josie Coburn. June 2014. "Multicriteria Mapping Manual Version 1.0."

SWPS 2014-12. Anabel Marin, Lilia Stubrin and Patrick van Zwanenberg. June 2014. "Developing capabilities in the seed industry: which direction to follow?."

SWPS 2014-13: Mariana Mazzucato, Carlota Perez. July 2014. "Innovation as Growth Policy: the challenge for Europe."

SWPS 2014-14: Daniele Rotolo, Loet)Leydesdorff . July 2014. "Matching MEDLINE/PubMed Data with Web of Science (WoS): A Routine in $R$ language."

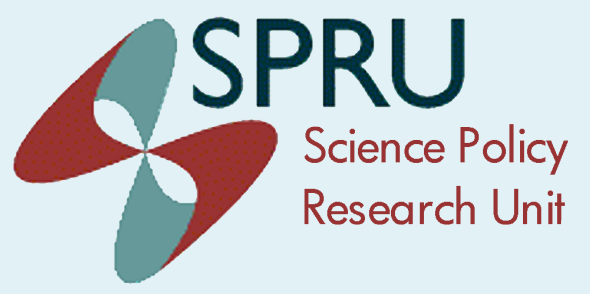

\section{SPRU}

Science Policy Research Unit University of Sussex

Falmer, Brighton, BN1 9SL, UK www.sussex.ac.uk/spru 